\title{
SOBRE LA ESPECIFICIDAD DEL ATEÍSMO MODERNO
}

\section{ON THE SPECIFICITY OF MODERN ATHEISM}

\author{
Diego SÁnchez MecA ${ }^{1}$ \\ Facultad de Filosofía
}

UNED

\begin{abstract}
Resumen: En este ensayo se trata de analizar el tipo específico de ateísmo que caracteriza y peculiariza al pensamiento filosófico contemporáneo, representado en tres autores: Marx, Nietzsche y Freud. Para todos ellos la religión es una ilusión que debería quedar superada y desplazada por la ciencia, el progreso de la civilización y la autosuperación del individuo. La religión es el fruto de una proyección subjetiva, es decir, de una invención a la vez individual y colectiva, de naturaleza compensatoria, propia de un estadio infantil e inmaduro de los individuos y de la sociedad que debería superarse para acceder a una situación de más libertad, de más salud psíquica y, en definitiva, de mejor realización humana. Por eso, estos tres pensadores exhiben su ateísmo en íntima conexión con una crítica de la cultura cuyo fin es propugnar una liberación del ser humano de todo aquello que lo aliena, lo anula o lo neurotiza, es decir, de todo aquello que le impide ser todo lo que los seres humanos podríamos llegar a ser. No se trata, por tanto, de una destrucción de lo religioso como dimensión existencial propia y distintiva de lo humano, sino de una crítica de determinadas expresiones que la religión y la fe en Dios han adoptado en nuestra cultura.
\end{abstract}

Palabras clave: Religión, ateísmo, Marx, Nietzsche, Freud.

\footnotetext{
${ }^{1}$ Departamento de Filosofía, UNED. C/ Paseo Senda del Rey, 7. Madrid (28040). E-mail: dsanchez@fsof.uned.es
} 
Авsтract: In this paper we try to analyze the specific type of atheism that characterizes and distinguishes contemporary philosophical thought, represented by three authors: Marx, Nietzsche and Freud. Religion is for them an illusion that should be overcome and displaced by science, the progress of civilization, and the individual self-improvement. Religious is the result of a subjective project, that is, an invention that is, at the same time, individual and collective, of a compensatory nature, belonging to an infantile, immature stage of individuals and society which should be overcome in order to gain access to a situation $\mathrm{f}$ greater freedom, greater psychological health and, in short, improved human fulfilment. Because of this, these three thinkers exhibit their atheism in intimate conncection with a criticism of culture, in order to foment the liberation of human beings from all that alienates, annuls, or neuroticizes them, that is, everything that prevents them from being all that they could be. It is not, therefore, a destruction of all that is religious as an existential dimension in itself, something distinctive to being human, but rather a criticism of certain expressions that religion and faith in God have adopted in our culture.

KeYwords: Religion, atheism, Marx, Nietzsche, Freud.

Que Marx, Nietzsche y Freud son los tres grandes pensadores ateos de la filosofía europea postilustrada creo que es algo de todos suficientemente conocido. Es conveniente, sin embargo, especificar qué clase de ateísmo caracteriza y peculiariza al pensamiento de cada uno de estos autores y qué pueden tener en común. Si hubiera que señalar algún aspecto común en lo referente a la comprensión de la religión en estos tres autores, probablemente el que más inmediatamente salta a la vista es la caracterización que hacen de la religión como una ilusión que debería quedar superada y desplazada por la ciencia, el progreso de la civilización y la autosuperación del individuo. Por ejemplo, para Marx, la religión es la ilusión consolatoria que los seres humanos se procuran, a la manera de un opio, en situaciones sociales, económicas y políticas de injusticia e inhumanidad para evadirse de ellas y poder soportarlas. Nietzsche, por su parte, afirma que fueron los nihilistas, es decir, los despreciadores del cuerpo y de la tierra quienes inventaron las cosas celestiales, los trasmundos y a Dios como clave de bóveda de toda una construcción metafísica y moral de la vida que ha mostrado finalmente su nada constitutiva en nuestra época. Y Freud define la religión como la ilusión fruto de la estrategia de los impulsos inconscientes y ofrece analogías entre ella, 
los sueños y los síntomas neuróticos con los que se satisfacen de manera sustitutoria y disfrazada necesidades psicológicas.

Es decir, ninguno de estos autores afronta la religión y la creencia en Dios como un error en sentido lógico o gnoseológico señalando, por ejemplo, la falta de valor probatorio de estas o aquellas pruebas; ni tampoco, de manera directa, como una mentira en sentido moral, sino, que la afrontan como el fruto de una proyección subjetiva, es decir, de una invención a la vez individual y colectiva, de naturaleza compensatoria, propia de un estadio infantil e inmaduro de los individuos y de la sociedad que debería superarse para acceder a una situación de más libertad, de más salud psíquica y, en definitiva, de mejor realización humana. Por eso, estos tres pensadores exhiben su ateísmo en íntima conexión con una crítica de la cultura cuyo fin es propugnar una liberación del ser humano de todo aquello que lo aliena, lo anula o lo neurotiza, es decir, de todo aquello que le impide ser todo lo que los seres humanos podríamos llegar a ser. No se trata, por tanto, de una destrucción de lo religioso como dimensión existencial propia y distintiva de lo humano, sino de una crítica de determinadas expresiones que la religión y la fe en Dios han adoptado en nuestra cultura, así como de los efectos que han tenido contrarios a ese fin positivo que es la liberación de los seres humanos. Pues bien, vamos a analizar la formulación del ateísmo y la crítica a la religión en cada uno de estos tres autores.

En el caso de Marx ${ }^{2}$, partimos de esa definición que hemos señalado de la religión como la falsa conciencia del ser humano sobre sí mismo que se produce en condiciones sociales, económicas y políticas injustas. En este sentido, la religión forma parte de las superestructuras ideológicas sin las cuales tales condiciones injustas y opresivas no podrían mantenerse, de modo que su función habría sido la de narcotizar a los individuos para que soporten mejor la miseria, la explotación y la opresión. Puesto que somos seres sociales, los seres humanos nos encontramos siempre inmersos en un conjunto de relaciones de producción, de trabajo, de sistema político, de creencias y de costumbres que son como son sin que nuestra voluntad y libertad tengan muchas posibilidades de intervenir para cambiarlas sustancialmente. Este sistema de relaciones de producción y de trabajo es lo que constituye la infraestructura económica de nuestra sociedad, y por tanto es la base real sobre la que se levanta una superestructura jurídica

\footnotetext{
${ }^{2}$ Para la crítica de Marx a la religión véanse sus Tesis sobre Feuerbach y otros escritos filosóficos, Grijalbo, Barcelona,1974. También se consultarán con provecho sus Textos selectos, Gredos, Madrid, 2011 y sus Manuscritos: economía y fllosofía, Madrid, Alianza, 1981.
} 
(que son el derecho y las leyes vigentes) y una superestructura política (que es el Estado), a las que corresponden formas determinadas de conciencia social por parte de los individuos como son la moral, la filosofía, y naturalmente la religión.

Tenemos, por tanto, aquí uno de los principios más distintivos del pensamiento marxista, y es que las formas de producción de los medios materiales necesarios para vivir condicionan de manera decisiva todo el proceso social, político, pero también cultural y espiritual de una sociedad. Con esto, Marx se opone a lo que afirmaba la filosofía tradicional, en el sentido de que no es el espíritu o la conciencia de los hombres lo que determina su ser, sino al contrario, su ser social y las condiciones de su medio económico y político son las que determinan su conciencia, su pensamiento y su cultura. O para decirlo más brevemente, la superestructura no es sino un subproducto de la infraestructura. Y esto significa que la cultura en su conjunto, o sea, la moral, la política, el arte, y, por supuesto, la religión, no serían más que un reflejo de las condiciones económicas en las que se vive, por lo que no serían más que ideología. Y aquí entramos en un aspecto muy polémico que es precisamente el específico del ateísmo marxista. Pues para el marxismo, ideología son todas las ideas y discursos con los que trata de justificarse y legitimarse el estado social de hecho, por lo que de ningún modo reflejan con veracidad esa situación, sino que la presentan falseada, tergiversada y enmascarada.

Lo que los seres humanos piensan y creen estaría siempre influido y hasta determinado, según el marxismo, por los condicionamientos económicos y políticos de la sociedad en la que se vive. Y esto es lo que genera la alienación de esos individuos, alienación que Marx interpreta en los mismos términos que lo había hecho antes Feuerbach. Para Feuerbach, la alienación es un mecanismo de proyección objetivadora que los seres humanos hacen indeliberadamente de productos de su propia actividad y fantasía, tomándolos luego como realidades en sí y sometiéndose a ellos ${ }^{3}$. Por ejemplo, alienación sería ese tipo de proyección que tiene lugar, de un modo particularmente relevante, en la religión y que consiste en que en vez de ser Dios quien crea al hombre, es el hombre -dice Feuerbachquien crea a Dios. Por lo tanto la religión es alienación que conduce a la evasión de la realidad hacia un mundo trascendente lleno de creaciones ilusorias que sirven de consuelo y de esperanza ante este "mundo injusto y sin esperanza". Las religiones -dice Marx-surgen de esas situaciones de injusticia para consolar a

${ }^{3}$ Feuerbach, Ludwig, La esencia del cristianismo, Madrid, Trotta, 2009. 
los individuos del sufrimiento que les produce un mundo malvado, desalmado e inhumano, ya que sin el opio de la religión, estas situaciones no podrían subsistir.

De ahí que la religión induzca a apartar la mirada de este mundo para volverse hacia la esperanza en un más allá. Al prometer una felicidad en la otra vida, enseña a aceptar la desdicha en la tierra y disuade de la protesta y de la rebelión. Adormece, en definitiva, la lucha revolucionaria y entorpece así la liberación de los seres humanos. Por eso dice Marx que la religión, como el resto de la ideología, se encuentra siempre e invariablemente al servicio y en beneficio de la clase dominante. Y esta es la razón por la que rechaza todas las religiones y niega toda transcendencia. La falsa conciencia de la religión debería quedar superada, según él, como primer requisito para cambiar el mundo de tal modo que dejara de necesitar semejantes ilusiones ${ }^{4}$.

En cuanto a Nietzsche $e^{5}$ hay algunas analogías entre este ateísmo de Marx y el de Nietzsche, como vamos a ver, aunque Nietzsche, en realidad, lo que hace es un análisis de la religión en la historia de Occidente, así como de los efectos y consecuencias que la fe en el Dios cristiano ha supuesto para el desarrollo y el estado actual de nuestra civilización occidental. Todos saben, sin duda, o lo habrán oído decir, que Nietzsche es el filósofo del "Dios ha muerto". Y algunos hasta creen que Nietzsche es quien lo ha matado. Esto sería, creo yo, tener una idea demasiado elevada del poder de Nietzsche, por lo que no tiene mucho sentido eso que se cuenta sobre cierta inscripción encontrada en el muro de Berlín. Por lo visto había un grafiti que decía: Dios ha muerto, firmado Nietzsche. Y debajo otro que decía: Nietzsche ha muerto, firmado Dios, como desafiando a ver cuál de las dos afirmaciones era la más verdadera. No. Yo creo que este no es el modo de enfocar la cosa. Nietzsche no es el asesino de Dios, ni hubiese podido serlo por mucho que lo hubiese querido ser. Borrar a Dios de nuestras vidas y

\footnotetext{
${ }^{4}$ Para seguir leyendo sobre el ateísmo marxista, aún sigue siendo sugerentes los libros de Gardavsky, Vítezslav, Dios no ha muerto del todo: reflexiones de un marxista sobre la Biblia, la religión y el ateísmo, Salamanca, Sígueme, 1972, y el de González Ruiz, José María, Marxismo y cristianismo frente al hombre nuevo, Fontanella, Madrid, 1969. Un enfoque más reciente es el de MacIntyre, Alasdair C., Marxismo y cristianismo, Buenos Aires, Nuevo Inicio, 2007.

${ }^{5}$ La crítica de Nietzsche a la religión está diseminada por toda su obra. Son muy importantes, no obstante, algunas obras últimas como El Anticristo, Crepuisculo de los ídolos o Más allá del bien y del mal. También las primeras obras de madurez, Humano, demasiado humano y La gaya ciencia, que pueden encontrarse en Nietzsche, F., Obras Completas, edición de D. Sánchez Meca, vol. III, ed. Tecnos, Madrid, 2013. Así mismo son insustituíbles sus fragmentos póstumos, cfr. Nietzsche, F., Fragmentos póstumos, edición de D. Sánchez Meca, Madrid, Tecnos, 2007-2010, 4 vols.
} 
de nuestra historia no es un acontecimiento pensable como un acto voluntarista o un ejercicio terrorista de destrucción de alguien en particular aunque se trate de Nietzsche.

La expresión "Dios ha muerto", lo único que significa es la constatación, ya en tiempos de Nietzsche (o sea en el s. XIX), de que la fe en el Dios cristiano se había debilitado hasta el punto de no servir ya de fundamento a los valores y a las verdades sobre las que se había sostenido antes la civilización europea. Esta disolución de la fe en Dios fue el resultado de todo el proceso de críticas que tuvieron lugar por parte de los científicos y filósofos modernos, especialmente franceses e ingleses, en lo que se ha dado en llamar el proceso de secularización. Y Nietzsche lo que hace es proseguir este proceso de desenmascaramiento y deslegitimación con la conciencia de que al hacerlo así está respondiendo a la exigencia de búsqueda de la verdad y de autenticidad moral que siempre habían propugnado la metafísica y la moral cristiana. Porque es esta exigencia la que termina conduciendo finalmente a la disolución de Dios y de la religión, a la manera de un proceso de purificación que no tolera ya lo falso e ilusorio con lo que muchas veces, históricamente, se han construido la teoría y la praxis de nuestra cultura occidental.

No creo que sea preciso aclarar que este dios que muere es, en realidad, el Dios de la teología, de la metafísica y de la política. O sea, es el Dios de la ontoteología que al fin se ha descubierto como simple ilusión, o sea, como máscara de la nada, pero a la vez, sin embargo, como instrumento importante de determinadas formas de ejercicio histórico del poder. Como para Marx, también para Nietzsche la fe surge como respuesta al sufrimiento y es creación infantil de ilusiones sustitutorias. Sólo que para él eso ha formado parte de la estrategia de unos pocos que astutamente lograron dominar a grandes masas mediante la estrategia de utilizar a Dios como el principal instrumento para debilitar y domesticar al ser humano. La estrategia consistía en arrebatar, mediante el concepto de pecado y de culpa, el amor por la vida, la autoafirmación, la adhesión a este mundo y a la felicidad de esta tierra. La religión se habría desarrollado así como una especie de intoxicación para sumir a los seres humanos en el desprecio de sí mismos logrando convertir al europeo de hoy en un animal enfermo.

En este sentido, la religión cristiana habría funcionado promoviendo unos valores y unas actitudes que han favorecido la rebañización de las masas, la desaparición sistemática de las individualidades fuertes, independientes y creativas, convirtiendo, por tanto, nuestro mundo en el reino del nihilismo y de la 
mediocridad. Por esta razón, Nietzsche plantea su crítica a la religión cristiana como el primer paso de un proyecto de transvaloración de los valores morales. $\mathrm{Si}$ el Dios cristiano ha servido durante siglos de fundamento de todo el edificio de verdades y valores sobre los que se sostenía nuestra cultura nihilista, la muerte de Dios implica que ahora los seres humanos podemos darnos a nosotros mismos unos valores, unas metas y unos fines que proporcionen un nuevo sentido a nuestra vida y ofrezcan a nuestro mundo un nuevo centro de gravedad. Para Nietzsche, la muerte de Dios ha sido, en este sentido, un acontecimiento positivo, porque una vida sometida a un Dios eterno e inmutable no podía evolucionar, ya que tenía que atenerse a un orden de valores y verdades fijado de una vez por todas. Como después para Sartre, Nietzsche piensa que este Dios no debería existir, ya que si existiese el ser humano no sería libre para crear su ser individual, su sociedad y su proyecto de vida.

Ahora es posible una transvaloración, es decir, una nueva creación de valores que se base, no en la promoción de la debilidad y el rechazo a esta vida, sino en su aceptación y afirmación, a ejemplo del paganismo antiguo que sirvió de fuente a una cultura sana y creativa, como fue la de los antiguos griegos. Lo que caracterizó a esta religión pagana, dice Nietzsche, fue que nunca pretendió la moralización de la sociedad, sino que su razón de ser fue la exaltación de una imagen de la felicidad representada en la pluralidad de los dioses olímpicos. Es decir, no consistía en la sacralización de ningún código moral que proclamara las tablas de un bien y de un mal trascendentes, sino que era la expresión sublimada de impulsos eróticos que tienden al amor universal y de una crueldad que se liberaba mediante los sacrificios y rituales litúrgicos.

Por tanto, contra la religión cristiana como consuelo, opio, deseo de muerte, neurosis, martirio, crucifixión, y obsesión con el dolor, Nietzsche propone abrir paso ahora a la religión como serenidad y afirmación de la vida en su totalidad simbolizada en la figura del dios Dioniso. Ya no se identificaría, por tanto, la religión con una Iglesia en cuanto institución de poder que conduce a las almas como un rebaño, sino que se entendería como libre espiritualidad y vida interior, que siente la vinculación del hombre con la tierra y le impulsa a identificarse con la totalidad de todo lo que existe, afirmándola y comprendiéndose parte de ella. Esta religión promovería un nuevo amor espiritualizado y un profundo 
reconocimiento hacia la vida, al enseñar al individuo a vivir religado con la totalidad universal perfecta en todos los momentos de su devenir ${ }^{6}$.

Veamos, por último lo que nos dice Freud ${ }^{7}$. Para Freud, la religión nace de la misma necesidad que las demás formas de la cultura (ciencia, técnica, política, etc.), que es la necesidad de defensa del individuo humano frente a las fuerzas de la naturaleza y la violencia de los demás hombres. Su origen es, por tanto, el desamparo del adulto, que continua y repite el desamparo infantil. La mayoría de los seres humanos estamos destinados, según este autor, a seguir siendo siempre niños, y por eso, cuando se trata de la religión, lo que se hace es investir a las potencias desconocidas y terribles del mundo y de la vida con los rasgos de la imagen paternal. La fuente de la religión, lo mismo que la de la moral, es la situación de indefensión propia del ser humano y el miedo que nace de esta indefensión, ya se trate de un miedo real o de un miedo neurótico, frente al cual se recurre a la figura del padre como defensor y protector.

Ahora bien, lo específico de la religión es, para Freud, que tanto sus creencias como su ceremonial remiten a una realización de ese deseo del padre según el modelo del sueño, o sea, produciendo ficciones, mitos, relatos que entran todos en su concepto de ilusión. La ilusión sería, por tanto, una estratagema del deseo para realizarse al margen del principio de realidad. Y esto es lo que permite a Freud ver una simple diferencia de grado entre la mitología religiosa y el delirio, porque el conflicto con la realidad está disimulado en la ilusión mientras que se hace patente en el delirio. Por esta razón, algunas creencias religiosas resultan, en este sentido, para él, claramente delirantes. En cualquier caso, la religión es, para Freud, la realización de un deseo disimulado según el modelo proyectivo-imaginativo propio del sueño, que surge de una situación de sufrimiento y malestar profundos como deseo de consuelo (o sea, lo mismo que para Marx y para Nietzsche). Puesto que el ser humano es un ser básicamente infeliz al no poder conciliar nunca la satisfacción de sus deseos más profundos con la tarea histórica de la cultura y con su realización objetiva como hombre, necesita de una institución como la religión que le ofrece justamente, junto al rostro severo y cruel de la prohibición y del castigo, también la cara amable del perdón y del

\footnotetext{
${ }^{6}$ Para la crítica de Nietzsche a la religión, sigue siendo imprescindible el libro de Valadier, Paul, Nietzsche y la crítica del cristianismo, Madrid, Cristiandad, 1982. También continúa siendo interesante el de Jaspers, Karl, Nietzsche y el cristianismo, Buenos Aires, Leviatán, 1990. ${ }^{7}$ Las principales obras en las que Freud desarrolla su crítica a la religión son El porvenir de una ilusión, Totem y tabú y Moisés y el monoteísmo, que pueden consultarse en Freud, S., Obras completas, ed. James Strachey y Anna Freud, Buenos Aires, Amorrortu, 1972 ss.
} 
consuelo. Por eso es por lo que históricamente se han representado a los dioses en forma humana de modo que el individuo los pueda ver frente a sí como seres susceptibles de ser aplacados e influidos. Se ha creado, por ejemplo, la figura de la Providencia, como dios benévolo capaz de dejarse sobornar con ofrendas y promesas para realizar a cambio los deseos del hombre, porque sólo un cosmos regulado por esta providencia favorable, justa, paternal y sabia resulta adecuada a los deseos del hombre. De modo que la religión promete así al ser humano alivio de su pesada carga de sufrimiento, le reconcilia con su destino ineluctable y le compensa de todos sus sacrificios.

La historia de las religiones habría evolucionado, en consonancia con esto, en función de sucesivos desplazamientos de esta figura paterna, de modo que primero esa figura paterna es el totem, luego son los espíritus y los demonios, luego es una pluralidad de dioses y, finalmente, es un dios único. Por tanto, el momento culminante de la historia de las religiones sería el monoteísmo judaico y luego cristiano, que es el momento en el que la multiplicidad de lo divino se reduce a una persona única, de tal modo que la relación de los individuos con él puede adoptar ya esa intimidad y esa cercanía que es propia de las relaciones infantiles del niño con su padre. Por tanto, nótese que el consuelo ofrecido por la religión en compensación por el sufrimiento de la vida está implicando un retroceso de los individuos a la situación infantil anterior a ese sufrimiento. El mecanismo sobre el que se forma y se consolida la religión sería, pues, éste: del mismo modo que todas las situaciones de impotencia y de dependencia en la que los seres humanos nos encontramos repiten nuestra situación infantil de desprotección y desamparo, también la consolación de la religión actuaría repitiendo y reactivando el prototipo de todas las figuras consoladoras que es la figura del padre protector y omnipotente, que queda así instituido como Dios. En definitiva, en la religión, el ser humano seguiría siendo presa de la nostalgia paterna, porque nunca deja de ser débil como un niño. Entonces, si todo desamparo es nostalgia del padre, todo consuelo es reiteración del padre. Y por eso, frente a la desgracia, la violencia, el terror, las catástrofes, el hombre-niño sigue recurriendo a dioses a imagen del padre.

Una vez aclarado lo que para Freud constituye la esencia de la religión, querría decir un par de cosas más, una sobre lo que piensa acerca de la práctica de la religión y otra sobre cuál fue su origen en los comienzos de nuestra civilización. En relación con las prácticas religiosas, Freud establece una significativa analogía entre estas prácticas y la neurosis obsesivo-compulsiva. En un escrito de 1907, titulado Actos obsesivos y ejercicios religiosos, la práctica religiosa, y, más 
concretamente, la observación de un ritual, de una ceremonia o de un sacramento, es comparada elemento a elemento con el ceremonial del neurótico. En ambos casos, dice Freud, se da el mismo cuidado por respetar los detalles del ritual, la misma atención por no omitir nada, la misma tendencia a complicar su ordenamiento, la misma tortura de conciencia cuando se ha omitido algún fragmento. $Y$, por último, el mismo carácter defensivo y protector del ceremonial frente a un vago miedo al castigo procedente de fuera. Naturalmente, en el caso de Freud, esta comparación apunta a la pregunta: ¿habría que comprender entonces la neurosis obsesiva como una cierta religión privada y la religión como una neurosis obsesiva universal? En cualquier caso, sea cual sea la respuesta que se le quiera dar a esta pregunta, lo cierto es que esta analogía se ha utilizado en exceso para presentar cualquier práctica religiosa como una caricaturización de la neurosis, y esto no puede hacerse así sin más, sin antes no haber determinado razonadamente si toda religión o religiosidad puede quedarse reducida a esta caricatura trágico-cómica, o bien se trata sólo de determinadas formas regresivas de religión que, en efecto, suponen y se aproximan a la neurosis.

La segunda cosa a la que quería referirme, ya en el ámbito del psicoanálisis de la cultura, es a esa reconstrucción de los orígenes de la humanidad que Freud lleva a cabo en su obra Totem y tabú, en la que presenta la figura de Dios como la proyección de la omnipotencia del deseo según el modelo de la paranoia. Ayudándose de estudios etnológicos y antropológicos, elabora en esa obra una especie de mito de los orígenes que dice lo siguiente: la sociedad humana habría dado comienzo con un crimen, concretamente con un parricidio, porque en la horda prehumana, un padre tiránico y cruel impedía a sus hijos tener contacto sexual con las mujeres que él tenía sólo para sí, de manera que los hijos se unieron y mataron al padre. Pero como ese padre era al mismo tiempo el defensor y el protector del clan, una vez cometido el crimen los hijos se arrepintieron y su remordimiento les llevó a estas dos cosas: Primera, a aceptar la ley del padre, o sea, la prohibición del incesto, con la que da comienzo la sociedad propiamente humana, y segunda, a instaurar una rememoración periódica de ese crimen originario con el establecimiento de un ritual en el que el animal-totem (que simboliza la figura del padre) es muerto y comido su cuerpo y bebida su sangre. Este ritual de rememoración disfrazada de la muerte violenta del padre tendría la función de reavivar la reconciliación con su imagen interiorizada y sublimada, por lo que, con el tiempo, este totem se terminó convirtiendo en Dios.

La explicación que da Freud de esta institución de Dios es la que ya hemos dicho antes, o sea, si la angustia es nostalgia del padre, el consuelo tiene que ser 
reiteración del padre. En cuyo caso, también aquí la explicación freudiana apunta a la pregunta: ¿sería entonces la religión una pura repetición monótona y casi neurótica de sus propios orígenes arcaicos? Y también, como antes, creo que no todas las formas de religión y de religiosidad pueden quedar reducidas a esto, sino sólo aquellas que han hecho, por ejemplo, un mal uso de la culpabilización y del pecado para hundir a los individuos en la regresión, o que han creado mecanismos de consuelo promoviendo determinado tipo de devoción interesada e idólatra que mantiene a los individuos fuera del principio de realidad ${ }^{8}$.

Bien, no querría terminar sin decir que, según me parece, un ateísmo como el de estos tres autores no puede agotar su significación en la simple negación y destrucción de la religión a partir de sus efectos negativos en la cultura o en la psicología de los individuos, sino que debe tener también el sentido de servir para despejar el horizonte a lo que podríamos llamar, de manera paradójica, una cierta religiosidad postreligiosa. Lo que critican y tratan de destruir Marx, Nietzsche y Freud es la religión y sus secuelas como fenómeno histórico-cultural, no tanto la religiosidad como actitud existencial y personal que debe ser propia de cualquier ser humano que se pregunta por el sentido de su vida y el valor de su existencia ${ }^{9}$. En este sentido, decía Paul Tillic, que la clave para comprender la situación de desorientación del hombre contemporáneo es la pérdida de su dimensión de profundidad. Nuestro mundo, tan avanzado científica y técnicamente, ha creado un entorno social que impulsa a los individuos hacia delante en dirección horizontal. Es decir, no tiene actualidad preguntarse hoy por el sentido de la vida, de dónde venimos, adónde vamos, qué debemos hacer, qué somos los seres humanos. Si la dimensión de profundidad es hacerse apasionadamente estas preguntas y estar abierto a una respuesta, entonces esta dimensión es algo que tienen en común la filosofía y esa religiosidad que no tiene por qué estar en dependencia de ninguna religión concreta. Yo creo que es posible una religiosidad postreligiosa, y creo que lo que mejor la definiría sería justamente esta dimensión de profundidad de la que habla Tillic ${ }^{10}$.

\footnotetext{
${ }^{8}$ Para la crítica del psicoanálisis a la religión es sugerente el libro de Kristeva, Julia, Al comienzo era el amor: psicoanálisis y fe, Barcelona, Gedisa, 2002

${ }^{9}$ Sobre la discusión general acerca del ateísmo son orientadores los libros de Puente Ojea, G., Ateísmo y religiosidad: reflexiones sobre un debate, Madrid, Siglo XXI, 2005 y, del mismo autor, Elogio del ateísmo: los espejos de una ilusión, Madrid, Siglo XXI, 1997.

${ }^{10}$ Véase, sobre todo, Tillic, P., Filosofía de la religión, Buenos Aires, Megápolis, 1973. Otras obras suyas importantes son Teología de la cultura y otros ensayos, Buenos Aires, Amorrortu, 1974 y Teología sistemática, Salamanca, Sígueme, 1982, 3 vols.
} 
El ser humano ha demostrado a lo largo de su historia una amplia capacidad para comprender y transformar el mundo, y hoy le anima la idea de que ningún límite se impone ya a esta capacidad. Qué sea lo que empuja así a los seres humanos hacia delante, en dirección horizontal, es difícil saberlo. En su caminar por el espacio y el tiempo, al ir transformado el mundo, el ser humano ha ido convirtiendo en instrumento todo lo que le salía al paso, y eso ha hecho que también él mismo se haya convertido finalmente en instrumento. Sin embargo, a la pregunta de para qué haya de servir el instrumento, no sabe darle respuesta. Siente el vacío y lo absurdo de su vida en este funcionamiento ininterrumpido de producción de medios para fines que a su vez se convierten en medios y que no apuntan nunca a ningún fin último. De modo que la vida del individuo actual está llena a cada instante con algo que tiene que ser hecho, que tiene que ser visto, dicho, planeado o disfrutado. Vive, pues, en un movimiento incesante de cosas y actividades. Sin embargo, no puede saber lo que es profundidad sin quedarse quieto, en silencio y reflexionar sobre él mismo. Sólo cuando deja de preocuparse por lo de fuera puede experimentar la plenitud del instante aquí y ahora, de ese instante en el que espontáneamente se despierta en él la pregunta por el sentido de su vida. 


\section{Bibliografía}

FeUerbaCh, L. (2009), La esencia del cristianismo, Madrid: Trotta.

Freud, S. (1972), Obras completas, ed. James Strachey y Anna Freud, Buenos Aires: Amorrortu.

Gardavsky, V. (1972), Dios no ha muerto del todo: reflexiones de un marxista sobre la Biblia, la religión y el ateísmo, Salamanca: Sígueme.

González Ruiz, J. M. (1969), Marxismo y cristianismo frente al hombre nuevo, Madrid: Fontanella.

Jaspers, K. (1990), Nietzsche y el cristianismo, Buenos Aires: Leviatán.

KRISTEVA, J. (2002), Al comienzo era el amor: psicoanális y fe, Barcelona: Gedisa.

MacIntyre, A. C. (2007), Marxismo y cristianismo, Buenos Aires: Nuevo Inicio.

Marx, K. (1974), Tesis sobre Feuerbach y otros escritos filosóficos, Barcelona: Grijalbo,

- (1981), Manuscritos: economía y filosofia, Madrid: Alianza.

- (2011), Textos selectos, Madrid: Gredos.

Nietzsche, F. (2013), Obras Completas, edición de D. Sánchez Meca, vol. III, Madrid: Tecnos.

- (2007-2010), Fragmentos póstumos, edición de D. Sánchez Meca, Madrid: Tecnos, 4 vols.

Puente Ojea, G. (2005), Ateismo y religiosidad: reflexiones sobre un debate, Madrid: Siglo XXI.

— (1997), Elogio del ateísmo: los espejos de una ilusión, Madrid: Siglo XXI.

VAladier, P. (1982), Nietzsche y la critica del cristianismo, Madrid: Cristiandad.

Recibido: 31/03/2016

Aceptado: 19/09/2016

Este trabajo se encuentra bajo una licencia de Creative Commons Reconocimiento-NoComercial-SinObraDerivada 4.0 Internacional

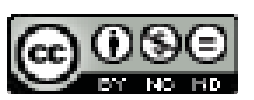

ÉNDOXA: Series Filosóficas, n. 38, 2016, pp. 297-309. UNED, Madrid 
